\title{
IN VITRO STUDY OF ANTIMICROBIAL AND ANTIOXIDANT ACTIVITIES OF OXALIC ACID-DERIVED BIOACTIVE CHELATING AGENT
}

\author{
DAISY SELASTEEN $\mathrm{F}^{1 *}$, ALFRED CECIL RAJ $\mathrm{S}^{2}$ \\ ${ }^{1}$ Department of Physics, P. G and Research, Bishop Heber College, ${ }^{2}$ Department of Physics, St. Joseph's College, Tiruchirappalli, \\ Tamil Nadu, India. Email: fdaisyallen77@gmail.com
}

Received: 18 August 2018, Revised and Accepted: 10 November 2018

\section{ABSTRACT}

Objective: The aim of this study is to evaluate the biological potentials of sodium cadmium oxalate dihydrate complex prepared by a single diffusion method in the silica gel medium.

Methods: The present complex was derived by the oxalic acid using a single diffusion method in gel medium and tested for single-crystal X-ray diffraction, ultraviolet-visible (UV) spectrum (190-500 mm), and solubility (distilled water at $20-29^{\circ} \mathrm{C}$ ) studies. Antioxidant activity was determined by 2, 2-diphenyl-1-picrylhydrazyl assay, and antimicrobial activity was measured by agar well diffusion method.

Results: The present chelating complex was successfully synthesized by gel technique. The solubility of sodium cadmium oxalate dihydrate was moderately good for deionized warm water. The UV spectral studies confirmed the chelating $\mathrm{O}-\mathrm{H}, \mathrm{Na}-\mathrm{O}$, and C-O bonds of the newly synthesized complex for the optical and biological properties.

Conclusions: The metal-oxygen and oxygen-hydrogen bonds of the present newly synthesized sample much improved its optical, antimicrobial, and antioxidant activities and find its applications in the field of pharmaceutical and biomedical applications.

Keywords: Sodium cadmium oxalate, Single-crystal X-ray diffraction, UV, Solubility, Biological activities.

(c) 2019 The Authors. Published by Innovare Academic Sciences Pvt Ltd. This is an open access article under the CC BY license (http://creativecommons. org/licenses/by/4. 0/) DOI: http://dx.doi.org/10.22159/ajpcr.2019.v12i2.29193

\section{INTRODUCTION}

Oxalic acid is a natural chemotherapeutic void of troubling side effects and is a normal element in human blood and must be available to the immune system to fight against the diseases of cancer, viral, bacterial, and vascular conditions. It has a mean value of $288 \mathrm{mg}$ of anhydrous oxalic acid/100 $\mathrm{ml}$ of blood. When it drops below an effective level, the immune system can no longer protect the body from various diseases [1]. In the body, oxalic acid is joined with divalent cadmium $\left(\mathrm{Cd}^{2+}\right)$ metal to form crystals of the corresponding oxalates, which are then expelled in urine as minute crystals. The use of an oxalate to combined with a metal (as $\mathrm{Fe}, \mathrm{Na}, \mathrm{Cd}, \mathrm{Zn}$, and $\mathrm{Cu}$ ) in the body to form a chelate so that the metal loses its toxic effect or physiological activity is known as the chelating agents which are found to be potential candidates for the removal of heavy metals in the series of trisodium citrate $>$ disodium oxalate $>$ sodium sulfate has been reported [2]. The adequate chelating efficiency of sodium or potassium mixed metal complexes of oxalate has been reported [3] due to their better solubility in water. In addition to that, metal chelates have a tendency to increase the biological activities through the charge carrier distribution process by the presence of intermolecular hydrogen $\mathrm{O}-\mathrm{H} . . . \mathrm{O}$ bonds [4], $\mathrm{Cd}-\mathrm{O}$, and $\mathrm{Na}-\mathrm{O}$ asymmetric stretching bonds [5]. Hence, the chelating $\mathrm{O}-\mathrm{H} . . . \mathrm{O}$ bonds are liable to increase the hydrophilic and lipophilic properties of the central metal ions, probably leading to liposolubility and permeability through the lipid layer of cell membranes [6,7]. Recently, an octahedral cadmium complex having a tetradentate acyclic ligand with antimicrobial potency has been reported [8]. Some cadmium complexes have also been exposed to biological properties in vitro [9]. The significance of the present study mainly focuses the biological activities of the sodium cadmium oxalate by studying the better optical conductivity of the as-grown crystal to find its usefulness in the field of pharmaceutical and biomedical applications.

\section{METHODS}

The high-purity essentials such as cadmium chloride (LOBA Chemie, $99.95 \%$ assay), sodium chloride (LOBA Chemie, $99.95 \%$ assay), oxalic acid (LOBA Chemie, 99.99\% assay), and sodium metasilicate (LOBA Chemie, $99.9 \%$ assay) with AR grade were used as the starting materials in the single diffusion chemical reaction method at a temperature of $29^{\circ} \mathrm{C}$. ENRAF NONIUS CAD4 X-ray diffractometer (XRD) equipped with Mo K $\alpha$ radiation was worked to estimate the unit cell parameters of the as-grown crystals. The various analyses were carried out at ambient temperature. The diffused reflectance spectral analysis was carried out with the help of a LAMBDA 35 UV-visible spectrophotometer. The reflection spectrum was traced to the range of $190-1100 \mathrm{~mm}$. The antimicrobial activity was assayed against Escherichia coli (Gramnegative), Staphylococcus (Gram-positive), Aspergillus niger, and Candida albicans (fungus) using the agar well diffusion method [10]. Nutrient agar (Merck, Germany) was used as solid media for preparing the nutrient plates while the Mueller-Hinton broth was applied as liquid culture media in biological tests. Bacterial cultures such as E. coli (Gram-negative), Staphylococcus (Gram-positive), A. niger, and C. albicans (fungus) were bought from the Eumic Analytical Lab and Research Institute, Tiruchirappalli, Tamil Nadu, South India. Bacterial strains were maintained on nutrient agar slants (HiMedia) at $4 \pm 0.2^{\circ} \mathrm{C}$. Microbial cultures were subcultured in liquid medium (nutrient broth) at $37 \pm 0.2^{\circ} \mathrm{C}$ for $8 \mathrm{~h}$ and further used for the test $\left(10^{5}-10^{6} \mathrm{CFU} / \mathrm{ml}\right)$. These suspensions were prepared immediately before the test was carried out. The antioxidant activity of sodium cadmium oxalate dihydrate was determined by 2, 2-diphenyl-1-picrylhydrazyl (DPPH) free radical scavenging assay.

\section{Synthesis of sodium cadmium oxalate material}

The sodium cadmium oxalate crystal was grown by single diffusion technique in the silica gel medium. The gel was prepared to set in corning glass tube (length $200 \mathrm{~mm}$ and diameter $25 \mathrm{~mm}$ ) using sodium metasilicate (specific gravity $1.04 \mathrm{~g}-\mathrm{cm}^{3}$ ) and oxalic acid $(1 \mathrm{M})$ in 10:8 volume ratio. The observed $\mathrm{pH}$ of gel solution was 4.75 . Gel formation took about a week. A mixture of cadmium and sodium chloride solutions was then added slowly along the walls of the glass tube. The chloride solution diffused deep into the gel as indicated by 
the Liesegang rings and their movements. The supernatant solution of the cadmium chloride was diffused into the gel column and reacted with the electrolyte sodium hydroxide mixed oxalic acid solution lead to the making of sodium cadmium oxalate crystal is given in the following reactions (1) and (2).

$$
\begin{aligned}
& 2 \mathrm{Na}_{2} \mathrm{SiO}_{3}+6 \mathrm{H}_{2} \mathrm{O} \rightarrow 2 \mathrm{H}_{4} \mathrm{SiO}_{4}+4 \mathrm{NaOH} \\
& 4 \mathrm{NaOH}+4 \mathrm{H}_{2} \mathrm{C}_{2} \mathrm{O}_{4}+2 \mathrm{CdCl}_{2} \rightarrow \mathrm{Na}_{4}\left[\mathrm{Cd}_{2}\left(\mathrm{C}_{2} \mathrm{O}_{4}\right)_{4} \cdot 4 \mathrm{H}_{2} \mathrm{O}\right]+4 \mathrm{HCl} .
\end{aligned}
$$

Subsequent diffusion of a supernatant solution to room temperature was improved that the structure of thick, transparent, and well-formed rectangular shaped colorless sodium cadmium oxalate dihydrate material is formed into the gel.

\section{Particle size}

The particle size of the sodium cadmium oxalate dihydrate was measured and refined by $0.30 \mathrm{~mm} \times 0.25 \mathrm{~mm} \times 0.20 \mathrm{~mm}^{3}$ using the full matrix least square technique employing the SHELXL program of single crystal XRD analysis method.

\section{RESULTS AND DISCUSSION}

\section{Single-crystal XRD analysis}

In the structure of sodium cadmium oxalate $\left[\mathrm{Na}_{4} \mathrm{Cd}_{2}\left(\mathrm{C}_{2} \mathrm{O}_{4}\right)_{2} 4 \mathrm{H}_{2} \mathrm{O}\right] \mathrm{n}$ complex as exhibited in Fig. 1, the repeat unit has two oxalate groups, one cadmium (II) atom, two sodium atoms, and four water molecules. The present compound crystallized in monoclinic, space group $\mathrm{P}_{21 / n}$ with $a=12.83, b=11.43, c=14.11, \beta=113.02^{\circ}, V=1908.86 A^{3}, Z=8$, Dcalc $=2.578 \mathrm{Mg} / \mathrm{m}^{3}, \mathrm{M}=1481.84$, and $\mathrm{R}=0.0234$ based on 3752 observed reflections was calculated by single-crystal XRD method using SHELX program. The result of the structural analysis is shown in Table $1 \mathrm{inform}$ that the structure of the present complex is formed by the $\mathrm{Na}-\mathrm{O}$ and $\mathrm{Cd}-\mathrm{O}$ bonds in the two-dimensional network is further linked by the $\mathrm{O}-\mathrm{H}-\mathrm{O}$ hydrogen bonds to stretch into the three-dimensional structure. The oxalate ligand has an inversion center of the midpoint of the $\mathrm{C}-\mathrm{C}$ bond. Intermolecular hydrogen bonds $[\mathrm{O}-\mathrm{H} . . . \mathrm{O}]$ improve the optical

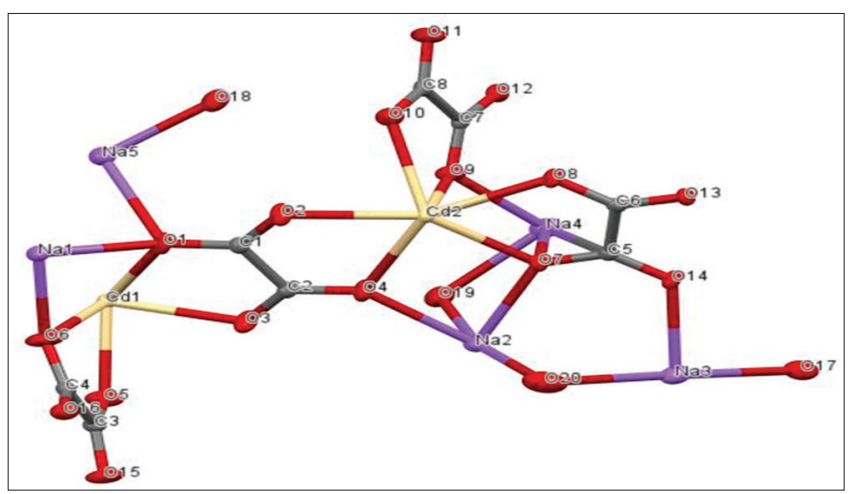

Fig. 1: Atom numbering arrangement of the sodium cadmium oxalate structure conductivity of the as-grown crystals. The eight oxygen atoms from the oxalate units and the water molecules bind the cadmium atom of the (Cd-O), (O-Cd), (Na-O), and (O-Na) bond distances are in the range of $2.3075 \mathrm{~A}^{\circ}-2.4827 \mathrm{~A}^{\circ}$ and $2.3633 \mathrm{~A}^{\circ}-2.3930 \mathrm{~A}^{\circ}$ build the repeated binding units of the sodium cadmium oxalate crystal into the polycrystalline material [11]. The centrosymmetric dimers of carboxylic acids are attributed to intermolecular resonance-assisted hydrogen bonds for the greater optical activities [12]. In the polymeric packing of sodium cadmium oxalate crystal, the framework stability is maintained by an extensive hydrogen bond network (Table 2) involving all 0 atoms of cadmium oxalate anion, sodium, and water molecules. The $\mathrm{H}_{2} \mathrm{O}$ molecules (Fig. 2) of the polymeric $\left[\mathrm{Na}_{2} \mathrm{Cd}\left(\mathrm{C}_{2} \mathrm{O}_{4}\right)_{2} 2 \mathrm{H}_{2} \mathrm{O}\right] \mathrm{n}$ crystal form the $\mathrm{O}-\mathrm{H} . . . \mathrm{O}$ hydrogen bonds in which the resonance-assisted strong hydrogen bond $(\mathrm{O}-\mathrm{H})$ is attributed to the optimized optical activities of the bimetallic crystal have been reported [13].

Ultraviolet-visible-near infrared (UV) diffused reflectance and absorption spectral studies

The diffuse reflectance from the absorbance spectrum of as-grown crystal in the UV-visible-NIR region was recorded in Fig. 3a. The optical band gap is determined by plotting absorbance versus energy of the material as shown in Fig. 3b. The linear fit of the curve on the energy axis is yielded the band gap as $4.2 \pm 0.3 \mathrm{eV}$ reveals that the high optical conductivity of the as-grown crystal leads to the better biological activities. The UV-Vis reflectance spectrum of the present complex shows two peaks at $245.94 \mathrm{~nm}$ and $310.34 \mathrm{~nm}$. The sharp absorption peaks observed in the UV spectrum are confirmed the electronic transitions to the $\mathrm{Na}^{+}$ion in the sodium cadmium oxalate complex. The first peak at $245.94 \mathrm{~nm}$ can be attributed to $\pi-\pi^{*}$ transition to the metal-oxygen (M-O) bonds within the sodium cadmium oxalate unit, while the second peak at $310.34 \mathrm{~nm}$ would be due to $\mathrm{n}-\pi^{*}$ transition to the oxygen-hydrogen $(\mathrm{O}-\mathrm{H})$ group of intermolecular hydrogen bonds of the water molecules [14]. On coordination complex, $n-\pi$ transition to ligand shifts to a longer wavelength. This indicates the coordination of ligand to metal. The cadmium ion has an oxidation number equal to +2 and coordination number equal to " 8 " due to the coordination of oxalate anion to a metal as a bidentate chelate. The cadmium ion has ground state 2D and the electronic spectra of the sodium cadmium oxalate dihydrate complex are exhibited maximum at $245.94 \mathrm{~nm}$ move to ligand-to-metal charge transfer [15]. On the coordination complex about the strong intermolecular bond lengths $\left(>2.3 \pm 0.03 \mathrm{~A}^{\circ}\right)$, the maximum optical activity is perceived by the $n-\pi^{*}$ transition to ligand shifts to a longer wavelength increase the chelating effect of the asgrown sample favors for the biological applications [16].

\section{Solubility study}

Solubility is one of the features for better biological studies of the asgrown sample has been reported [17] .Hence,the solubility of sodium cadmium oxalate was determined in the temperature range of $19^{\circ} \mathrm{C}$ to $32^{\circ} \mathrm{C}$ using double distilled deionized warm water as a solvent. Solubility studies were carried out in a constant temperature bath with the cryostat facility with an accuracy of $+0.03 \mathrm{~K}$.

The solution was stirred constantly for an hour to achieve the stabilization. After attaining the saturation, the equilibrium concentration

Table 1: Selected oxygen-hydrogen (O-H), cadmium-oxygen (Cd-O), and sodium-oxygen ( $\mathrm{Na}-\mathrm{O})$ bond lengths of sodium cadmium

\begin{tabular}{|c|c|c|c|}
\hline \multicolumn{2}{|c|}{ Selected oxygen-hydrogen bond lengths $(A)^{a}$} & \multicolumn{2}{|c|}{ Selected sodium-oxygen and cadmium-oxygen bond lengths $(A)^{2}$} \\
\hline $\mathrm{O}(17)-\mathrm{H}(17 \mathrm{~A})$ & $0.835(16) \pm 0.03$ & $\mathrm{Na}(1)-\mathrm{O}(6) \# 10$ & $2.2379(16) \pm 0.02$ \\
\hline $\mathrm{O}(17)-\mathrm{H}(17 \mathrm{~B})$ & $0.830(17) \pm 0.02$ & $\mathrm{Na}(1)-\mathrm{O}(1) \# 10$ & $2.2006(15) \pm 0.03$ \\
\hline $\mathrm{O}(18)-\mathrm{H}(18 \mathrm{~A})$ & $0.837(17) \pm 0.01$ & $\mathrm{O}(6)-\mathrm{Na}(1)$ & $2.2379(16) \pm 0.02$ \\
\hline $\mathrm{O}(18)-\mathrm{H}(18 \mathrm{~B})$ & $0.825(17) \pm 0.02$ & $\mathrm{O}(8)-\mathrm{Na}(3)$ & $2.3446(18) \pm 0.04$ \\
\hline O (19)-H (19A) & $0.841(17) \pm 0.04$ & $O(6)-C d(1)$ & $2.3840(17) \pm 0.01$ \\
\hline $\mathrm{O}(19)-\mathrm{H}(19 \mathrm{~B})$ & $0.835(17) \pm 0.02$ & $O(3)-C d(1)$ & $2.3619(16) \pm 0.02$ \\
\hline $\mathrm{O}(20-\mathrm{H}(20 \mathrm{~A})$ & $0.821(18) \pm 0.03$ & Cd (1)-0 (14) \#7 & $2.3101(15) \pm 0.01$ \\
\hline $\mathrm{O}(20)-\mathrm{H}(20 \mathrm{~B})$ & $0.825(18) \pm 0.01$ & Cd (1)-0 (16) \#7 & $2.4475(15) \pm 0.03$ \\
\hline
\end{tabular}
oxalate crystal 
of the solute was estimated gravimetrically. The same process was continual and the solubility curves were observed to $0.04 \mathrm{~g} / 100 \mathrm{ml}$ for sodium cadmium oxalate dihydrate at different temperatures (Fig. 4). It is observed from the curve that the solubility is found to increase within the rise in the temperature for sodium cadmium oxalate was due to the soluble nature of sodium oxalate in water. This result revealed that the improved solubility demands the sodium cadmium oxalate dihydrate complex is for further pharmaceutical research and applications.

\section{Antimicrobial screening studies}

Kirby-Bauer agar well diffusion assay

The nutrient agar medium was prepared and sterilized by autoclaving at $121^{\circ} \mathrm{C}$ and $15 \mathrm{lbs}$ pressure for $15 \mathrm{~min}$, then poured the agar medium into the sterile Petri plates and allowed to solidify. Then, the bacterial broth culture was cleansed on each Petri plate using sterile buds. Finally, the wells were made by the good cutter. The organic solvent extracts of leaves were added to each well aseptically.

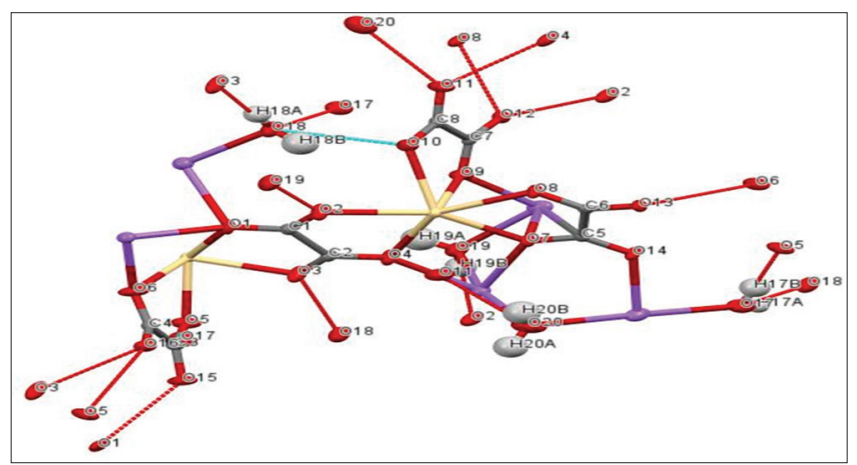

Fig. 2: The intermolecular hydrogen bonds metal-oxygen bonds of the sodium cadmium oxalate structure
This procedure was repeated for each Petri plate and they were incubated at $37^{\circ} \mathrm{C}$ for $24 \mathrm{~h}$. After incubation, the plates were observed in the zone of inhibition. The antimicrobial activity of metal complexes about the ligand of the as-grown title compound sodium cadmium oxalate dihydrate (Fig. 5) was tested by the disc diffusion technique. Results were compared with standard drug gentamycin at the same concentration. However, the antibacterial screening activity varied for different strains [18]. The increased bond length of the structure-activity relationships between $\mathrm{Na}$ $\mathrm{O}, \mathrm{Cd}-\mathrm{O}, \mathrm{C}-\mathrm{O}$, and $\mathrm{O}-\mathrm{H} . . . \mathrm{O}$ in sodium cadmium oxalate dihydrate improved the biological properties than the mononuclear complex $[19,20]$ has been explained by the Overtone's concept and Tweedy's chelation theory $[21,22]$. According to Overtone's concept of cell permeability, the lipid membrane that surrounds the cell favors the passage of only lipid-soluble materials since the liposolubility is an important factor that reins the antimicrobial activity. The increasing lipid solubility character of the metal chelate influences its permeation through the lipid layer of the microorganism which possibly leads to the breakdown of permeability barrier of cell process. During this process, increase to the lipophilic nature of the central metal (II) ions which favors its permeation more efficiently through the lipid layer of the microorganisms, thus building the chelate compounds is more antimicrobial activity [23]. It has also been observed that the concentration plays a key role in increasing the degree of inhibition so that when the concentration is increased, the antimicrobial activity also enhanced (Table 3). The quantitative assays gave minimum inhibitory concentration values of the range of $25-100 \mu \mathrm{g} / \mathrm{ml}$ are confirmed that the results are superior to the previously published values $[24,25]$. Coordination complex about antimicrobial active $\mathrm{C}=0$ part of metal(II) ions decreases the polarity of metal ions significantly due to the partial sharing of its positive charge with donor groups and delocalization of pi electrons [26] over the whole chelate ring resulting in high degree of inhibition [27] is due to the more antimicrobial activity of the present sample.

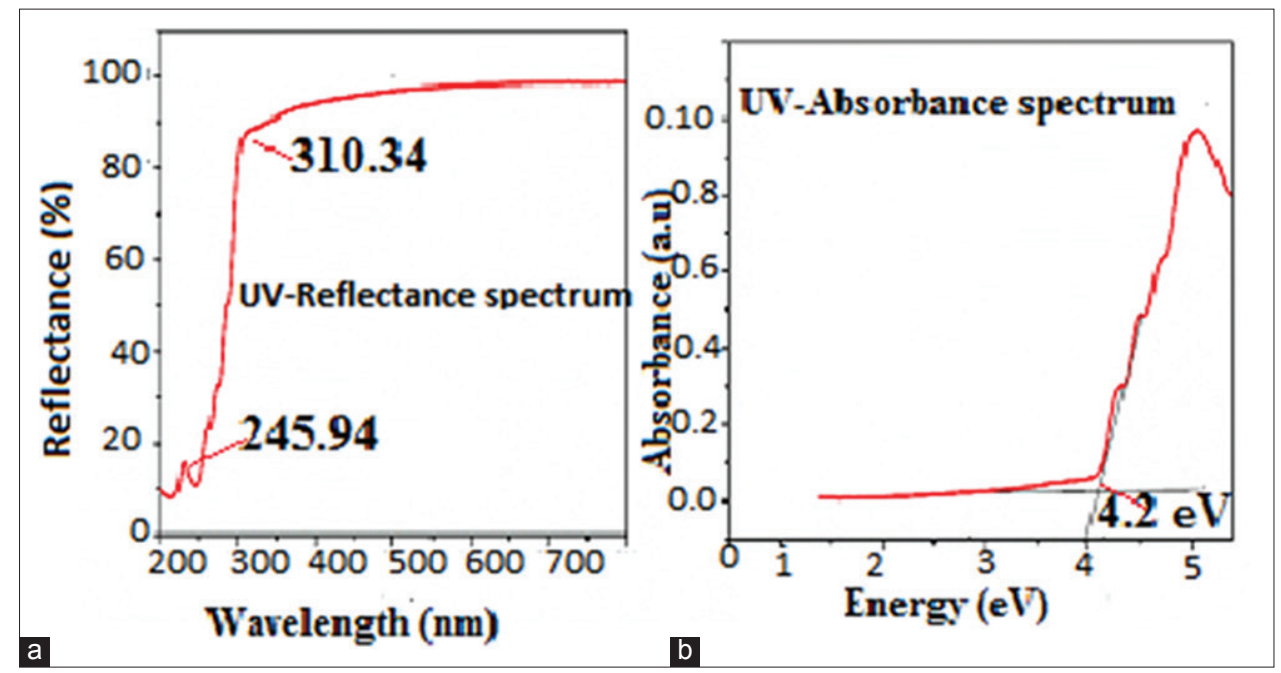

Fig. 3: Diffused reflectance spectrum of (a) sodium cadmium oxalate; absorbance spectrum of (b) sodium cadmium oxalate

Table 2: Selected hydrogen bonds and bond angles of the studied crystals

\begin{tabular}{|c|c|c|c|c|c|}
\hline S. No. & $\begin{array}{l}\text { Hydrogen bond formation } \\
{\left[0-\mathrm{H}_{\text {... O O }}\right.}\end{array}$ & $\begin{array}{l}\text { Bond length } \\
{[0-H]^{\mathrm{a}}(\mathrm{A})^{*}}\end{array}$ & 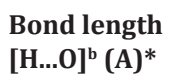 & $\begin{array}{l}\text { Bond length } \\
{[0 \ldots]^{c}(A)^{*}}\end{array}$ & $\begin{array}{l}\text { Bond angle } \\
(\mathrm{OHO})^{\mathrm{d}}(\mathrm{deg})^{*}\end{array}$ \\
\hline 1 & $\mathrm{O}(1)-\mathrm{H}(1 \mathrm{~B}) \ldots \mathrm{O}(7) \# 4$ & $0.87(3) \pm 0.02$ & $1.89(3) \pm 0.3$ & $2.726(2) \pm 0.4$ & $160(3) \pm 0.1$ \\
\hline 2 & $O(2)-H(2 B) \ldots O(6) \# 1$ & $0.83(3) \pm 0.01$ & $1.88(3) \pm 0.4$ & $2.6818(15) \pm 0.3$ & $162(3) \pm 0.1$ \\
\hline 1 & O (7)-H (7A)...O (7)\#6 & $0.87(3) \pm 0.02$ & $1.89(3) \pm 0.5$ & $2.726(2) \pm 0.2$ & $160(3) \pm 0.1$ \\
\hline 2 & $\mathrm{O}(2)-\mathrm{H}(2 \mathrm{~A}) \ldots \mathrm{O}(5) \# 8$ & $1.00(3) \pm 0.03$ & $1.70(3) \pm 0.2$ & $2.6918(15) \pm 0.1$ & $168(3) \pm 0.1$ \\
\hline
\end{tabular}

aSymmetric stretching mode of oxygen-hydrogen atoms, basymmetric stretching mode of hydrogen-oxygen atoms, casymmetric stretching mode of oxygen-oxygen atoms, ${ }^{\mathrm{d}}$ Angle between $\left\llcorner\mathrm{OHO}\right.$ water molecules. ${ }^{*}$ Mean \pm SD 
Antioxidant analysis

DPPH radical scavenging activity

DPPH assay was performed following standard protocol [28]. The present synthesized sample at various concentrations $(25-100 \mu \mathrm{g} / \mathrm{ml})$ was added to a $100 \mu \mathrm{M}$ solution of DPPH in methanol. The mixture was allowed to stand for $30 \mathrm{~min}$ to perform the complete reaction in the dark. The absorbance was measured at $517 \mathrm{~nm}$ using a UV spectrophotometer. The reduction in the absorbance of the DPPH solution indicates the free radical scavenging activities of the test sample. Methanol without the sample should be used as a control. DPPH radical scavenging activity will be calculated according to the following expression (1):

Radical scavenging activity $(\%)=\left(\frac{A_{O}-A_{S}}{A_{O}}\right) \times 100$

Where, $\mathrm{A}_{\mathrm{o}}=$ Absorbance of control and $\mathrm{A}_{\mathrm{s}}=$ Absorbance of sample. Control was the test solution without sample. IC50 is defined as the amount of antioxidant required to inhibit $50 \%$ of DPPH free radical under the experimental conditions. Ascorbic acid was taken as a standard solution. The antioxidant activity of the synthesized sodium cadmium oxalate dihydrate was studied by DPPH radical scavenging assay and compared with ascorbic acid (AA) as standard. Free radicals of reactive oxygen species and nitrogen species generations of cells are normal physiological activity. The excessive formation of these radicals in the human body causes cell damage by combining with the biomolecules such as protein, carbohydrates, and lipids, and finally leading to various diseases such as cancer, coronary heart disease, aging, neurodegenerative disorders, and diabetes [29]. Antioxidants play a significant role to control such oxidative stress situation by neutralizing these reactive radicals. Table 4 illustrates that DPPH scavenging activity is directly proportional to increase in the concentration of sodium cadmium oxalate dihydrate material. Sodium cadmium oxalate dihydrate showed an effective free radical scavenging activity of $84 \pm 0.13 \%$ at the concentration of $100 \mu \mathrm{g} / \mathrm{ml}$, whereas the standard L-AA showed $75 \pm 0.2 \%$ of scavenging activity of the same concentration. Due to the presence of the Inter-molecular and intra-molecular $\mathrm{O}-\mathrm{H}----\mathrm{O}$ hydrogen bonds are one of the key parameters to the higher optical conductivity of the as-grown sample. The more reactive oxygen atoms of these hydrogen molecules are responsible for the higher antioxidant activity of the present sample than the previously reported transition metal oxalate crystals $[30,31]$.

Table 3: Antimicrobial activity of sodium cadmium oxalate (II) complex

\begin{tabular}{llllll}
\hline \multirow{2}{*}{ Organism } & \multicolumn{3}{l}{ Minimum zone of Inhibition $(\mathbf{m m})^{*}$} & \multirow{2}{*}{ Control } \\
\cline { 2 - 5 } & \multicolumn{3}{l}{ Concentration $(\boldsymbol{\mu g} / \mathbf{m l})$} & \\
\cline { 2 - 5 } & $\mathbf{2 5}$ & $\mathbf{5 0}$ & $\mathbf{7 5}$ & $\mathbf{1 0 0}$ & \\
\hline Escherichia coli & $26 \pm 0.2$ & $30 \pm 0.1$ & $34 \pm 0.3$ & $40 \pm 0.2$ & $25 \pm 0.2$ \\
Staphylococcus & $22 \pm 0.3$ & $25 \pm 0.1$ & $28 \pm 0.2$ & $30 \pm 0.3$ & $15 \pm 0.1$ \\
Candida albicans & $20 \pm 0.3$ & $22 \pm 0.2$ & $24 \pm 0.2$ & $26 \pm 0.1$ & $18 \pm 0.3$ \\
Aspergillus niger & $22 \pm 0.3$ & $24 \pm 0.1$ & $26 \pm 0.2$ & $28 \pm 0.3$ & $18 \pm 0.1$ \\
\hline
\end{tabular}

*Mean \pm SD

\section{CONCLUSIONS}

Optically active single-crystal sodium cadmium oxalate has been obtained by single diffusion silica gel method. The results of the structural analysis were indicating that the complex formed by $\mathrm{O}-\mathrm{Na}-\mathrm{O}$ and $\mathrm{O}-\mathrm{Cd}-\mathrm{O}$ coordination bonds was a two-dimensional network structure which was further linked by $\mathrm{O}-\mathrm{H} \cdot \mathrm{O}$ hydrogen bonds to give a three-dimensional structure. On adding sodium, the triclinic structure of cadmium oxalate transformed into a monoclinic structure was confirmed by single-crystal XRD studies. The optical behavior of sodium cadmium oxalate crystal was studied by using UV-visiblenear infrared spectrum and found to be $98.4 \%$ of the transmittance. The wide transparency was due to the strong intermolecular $\mathrm{O}-\mathrm{Na}$, $\mathrm{O}-\mathrm{Cd}$, and $\mathrm{O}-\mathrm{H} \ldots \mathrm{O}$ bonds for having an efficient optical conductivity and biological activity of the sodium cadmium oxalate complex. The sodium cadmium oxalate complex showed good antimicrobial activity

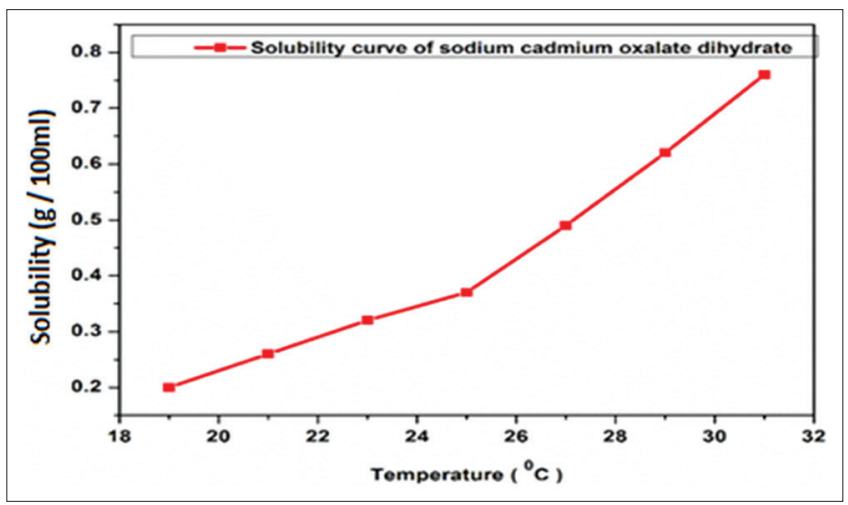

Fig. 4: Solubility of sodium cadmium oxalate

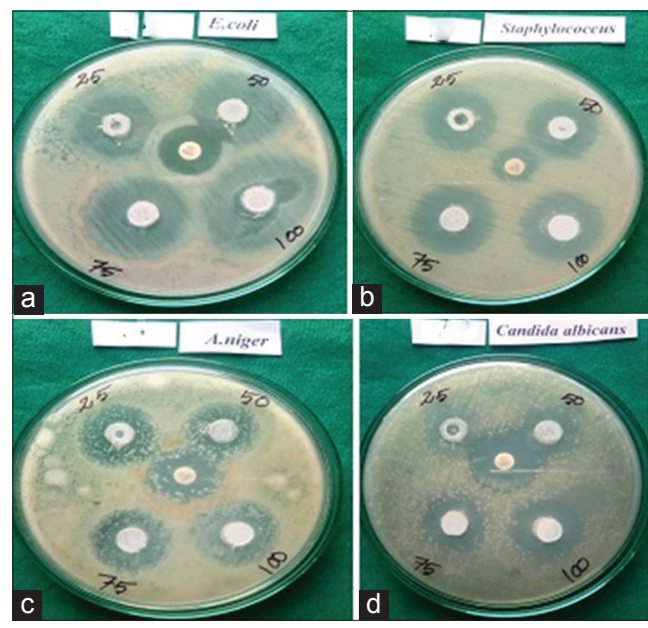

Fig. 5: Antibacterial activity of sodium cadmium oxalate against (a) Escherichia coli; (b) Staphylococcus; (c) Aspergillus niger; (d) Candida albicans

Table 4: Assessment of in vitro antioxidant activity of sodium cadmium oxalate complex and L-ascorbic acid in various concentrations

\begin{tabular}{lll}
\hline Name of the compound & Concentration $(\mu \mathrm{g} / \mathrm{ml})$ & Calculated antioxidant activity (a.u)* \\
\hline Sodium cadmium oxalate & 25 & $0.34 \pm 0.04$ \\
& 50 & $0.28 \pm 0.02$ \\
& 75 & $0.24 \pm 0.04$ \\
& 100 & $0.14 \pm 0.02$ \\
L-ascorbic acid & 05 & $0.48 \pm 0.03$ \\
& 10 & $0.43 \pm 0.02$ \\
& 15 & $0.39 \pm 0.04$ \\
& 20 & $0.36 \pm 0.03$ \\
\hline
\end{tabular}

*Mean \pm SD 
against E. coli (Gram-negative), Staphylococcus (G-positive), A. niger, and $C$. albicans (fungus) was attributable to the significant properties of its $\mathrm{O}-\mathrm{H} . . . \mathrm{O}$ resonance-assisted bonds, optical conductivity, and semi-polarity and liposolubility mechanisms. Further, the remarkable antioxidant activity of the present oxalic acid-derived complex proved that it may favor its application in the field of pharmaceutical and biomedical instrumentation.

\section{ACKNOWLEDGMENTS}

The authors are also thankful to University Grants Commission, Grant no.F.NO: MRP-5808/15 (SERO/UGC) for providing financial support under Minor Research Project (MRP) scheme.

\section{AUTHORS' CONTRIBUTION}

D.S. performed the study, experimental synthesis, and the computational analysis. All authors equally contributed to writing the manuscript and approved the final description.

\section{CONFLICTS OF INTEREST}

We declare that we have no conflicts of interest.

\section{REFERENCES}

1. Hodgkinson A. Oxalic acid in biology and medicine. FEBS Lett 1977;101:1-326

2. Atheer AM, Abdulqader MA, Jafaar MM. Studying of transition metal complexes containing oxalate ion with antibacterial activity. Int J Sci Eng Res 2015;6:855-67.

3. Williams AA, Macri RV, Gandour RD. Antimicrobial activity of longchain, water-soluble, dendritictri carboxylate amphiphiles. J Antimicrob Chemother 2007;59:451-8.

4. Schuster P. The Hydrogen Bond-Recent Development in Theory and Experiment. Vol. 89. Amsterdam: North-Holland Publishing Company; 1977. p. 348-9.

5. Dhanaraj PV, Rajesh NP, Vinitha G, Bhagavannarayana G. Crystal structure and characterization of a novel organic optical crystal: 2-aminopyridinium trichloro acetate. Mater Res Bull 2011;46:726-31.

6. Joseyphus RS, Nair MS. Antibacterial and antifungal studies on some schiff base complexes of zinc (II). Mycobiology 2008;36:93-8.

7. Thangadurai TD, Natarajan K. Mixed ligand complexes of ruthenium (II) containing $\alpha, \beta$-Unsaturated- $\beta$-ketoamines and their antibacterial activity. Transit Metal Chem 2001;26:500-4.

8. Montazerozohori M, Yadegari S, Naghiha A. Synthesis, characterization, electrochemical behaviour and antibacterial/antifungal activities of [Cd (L) X2] complexes with a new schiff base ligand. Serb Chem Soc 2014;79:793-804.

9. Patil NR, Gadagil S, Performance of chrom agar medium and conventional methods for detection of methicillin-resistant Staphylococcus aureus. Asian J Pharm Clin Res 2016;9:136-9.

10. Duddu MK, Guntuku G. Isolation, screening, and characterization of antibiotic producing actinomycetes from Kapuluppada plastic waste dumping yard, Visakhapatnam. Int J Pharm Pharm Sci 2016;8:221-9.

11. Raj AM. Optimized growth and characterization of cadmium oxalate single crystals in silica gel. Solid State Sci 2008;10:557-62.

12. Gilli G, Gilli P. Towards an unified hydrogen-bond theory. J Mol Struct 2000;552:1-15.

13. Zhong RQ. A novel 3D micro porous metal-organic framework of cadmium (II) oxalate with diamondoid network. Inorg Chem Commun 2008;11:951-3

14. Selasteen FD, Raj SA, Moses A. Synthesis and characterization in vitro antimicrobial and cytotoxicity testing of oxalic acid-derived cadmium chelating agents. Int J Pharm Pharm Sci 2018;10:80-6.

15. Ambujam K, Rajarajan K, Joseph P. Growth and characterization of a novel NLO crystal bis-glycine hydrogen chloride. J Cryst Growth 2006;286:440-4.

16. Abou-Hussein AA, Nelly HM, Linert W. Synthesis, + solvatochromism, and antimicrobial activities of new binuclear copper (II) mixed-ligand complexes in a ternary system with $\beta$-diketones and diamine ligands. J Coord Chem 2011;64:2592-605.

17. Kumar SS, Athimoolam S, Sridhar B. Hydrogen bonding motifs, spectral characterization, theoretical computations and anticancer studies on chloride salt of 6- mercaptopurine: An assembly of corrugated lamina shows enhanced solubility. J Mol Struct 2015;1098:332-41.

18. Selvarani M, Prema P. Evaluation of antibacterial efficacy of chemically synthesized copper and zerovalent iron nanoparticles. Asian J Pharm Clin Res 2013;6:223-7.

19. Kalainila P, Ravindran E, Renganathan S. Green synthesis of copper nanoparticle from Passiflora foetida leaf extract and its antibacterial activity. Asian J Pharm Clin Res 2017;10:69-73.

20. Abu-Hussein AA, Linert W. Redox, thermodynamic and spectroscopic of some transition metal complexes containing heterocyclic Schiff base ligands. Spectro chim Acta Part A 2009;74:214-23.

21. Tweedy BG. Plant extracts with metal ions as potential antimicrobial agents. Phytopathology 1964;55:910-8.

22. Madhavi K, Ramya GS. Synthesis, antioxidant and anti-inflammatory activities of ethyl 2-(2-cyano-3-(substituted phenyl) acrylamido)-4, 5-dimethylthiophene-3-carboxylates. Asian J Pharm Clin Res 2017;10:95-100

23. Budhwani S, Sharma S, Kalyane N. Synthesis of aryl (5- substituted benzofuran-2-yl) carbamate derivatives as antimicrobial agents. Asian J Pharm Clin Res 2017;10:377-81.

24. Zahid H, Chohan M. Ni (II), Cu (II) And Zn (II) metal chelates with some thiazole derived schiff-bases. Their synthesis, characterization and bactericidal properties. J Metal-Based Drugs 1999;6:75-80.

25. Arunachalam GA, Ramachandramoorthy T, Padmavathy S, Rani SA. Green synthesis and evaluation of biological impact of $\mathrm{Zn}$ (II), Cd(II) and $\mathrm{Hg}$ (II) complexes with phenylacetylurea and butanoate ion ligands. Int J Pharm Pharm Sci 2014;6:91-4.

26. Dharmaraja J, Subbaraj P, Esakkidurai T, Shobana S. Coordination behavior and bio-potent aspects of $\mathrm{Ni}$ (II) with 2-aminobenzamide and some amino acid mixed ligands - part II: Synthesis, spectral, morphological, pharmacological and DNA interaction studies. Spectrochim Acta A Mol Biomol Spectrosc 2014;132:604-14.

27. Jadon SC, Gupta N, Singh RV. Synthetic and biochemical studies of some hydrazine carbodithioic acid derivatives of dioxomolybdenum (VI). Ind J Chem 1995;34A:733-6.

28. Hu F, Lu R, Huang B, Liang M. Free radical scavenging activity of extracts prepared from fresh leaves of selected Chinese medicinal plants. Fitoterapia 2004;75:14-23.

29. Wu D, Cederbaum AI. Alcohol, oxidative stress, and free radical damage. Alcohol Res Health 2003;27:277-84.

30. Biradar VD, Mruthyunjayaswamy BH. Synthesis characterization and antimicrobial activity studies of some transition metal complexes derived from 3-chloro-N'-[(1E)-(2-hydroxy phenyl) methylene]-6methoxy-1-benzothiophene-2-carbohydrazide. Sci World Journal 2013;2013:451629.

31. Kapoor D, Rattan A, Kaur S, Bhardwaj R. Influence of cadmium on ant oxidative defence system, photosynthesis, level of osmolytes and ions uptake in Brassica juncea. Int J Pharm Pharm Sci 2016;8:204-8. 